\title{
EDITORIAL
}

\section{La creación de la Especialidad en Psiquiatría de la Infancia y la Adolescencia.}

\author{
Eudoxia Gay Pamos \\ Roque Prego Dorca \\ Fernando Márquez, Gallego
}

La infancia es el periodo de la vida donde se gesta el futuro. Desde el inicio del conocimiento de la psique, sabemos la importancia evolutiva y estructural de las experiencias infantiles. El sufrimiento mental y/o el enfermar en estas etapas precoces de la vida constituye un proceso complejo, profundamente enraizado en el entorno sociofamiliar y debe ser abordado de forma compleja, multifactorial, multisectorial, con conocimientos, herramientas y actitudes específicas y precisas. Por todo ello se hacía imprescindible contar con una formación postgrado específica y de calidad que, hasta ahora, no había existido en nuestro país.

La promulgación del conocido como Decreto de Troncalidad supone el primer gran cambio conceptual, estratégico y operativo que afronta un sistema formativo emblemático del Sistema Nacional de Salud (SNS) como es el MIR (MIR/ PIR/EIR en Salud Mental ), desde su inicio en 1978. Se abre así una nueva etapa. Durante este tiempo (más 36 años) este programa de formación ha conseguido acreditarse (más allá de sus problemas y deficiencias) como uno de los pilares esenciales de nuestro SNS, ha sido reconocido internacionalmente y asumido asimismo como referente de calidad por la ciudadanía y por varias generaciones de profesionales.

Durante su larga andadura, el modelo MIR ha sido objeto de múltiples consideraciones críticas dirigidas a pulirlo y modificar sus limitaciones e insuficiencias.

En el ámbito de la Salud Mental y ya desde antes de la creación de las Comisiones Nacionales de Especialidades, ha sido constante y unánime la reivindicación de completar la formación de los especialistas en salud mental con la aprobación de una especialidad que abordara, buscando la excelencia, la formación de los profesionales de salud mental que prestan atención integral a la población infantil y juvenil.

Tras estos años de esfuerzo continuado, finalmente se ha alumbrado dicha especialidad, equiparándonos, aunque tardíamente, a la mayoría de los países europeos. Su aprobación ha sido una de las dos únicas nuevas especialidades (además de genética clínica) del programa formativo del SNS. 
EDITORIAL

En lo que concierne a formación, la AEN-PSM desde los albores del programa MIR se marcó se como objetivo la creación de la especialidad de Psiquiatría del Niño y del Adolescente. Para ello nunca ha dejado de trabajar proactivamente con las asociaciones de familiares de niños con patología mental, con los distintos responsables ministeriales y autonómicos, cuidando su producción científica plasmada en artículos, mesas redondas, publicaciones y cuadernos tecnicos.

Un momento clave en este esfuerzo se produjo con la creación de la Comisión Promotora de la Especialidad, en la cual la AEN-PSM tuvo un papel fundamental. Desgraciadamente cambios ministeriales y políticos hicieron languidecer hasta la desaparición lo que parecía iba a suponer un paso fundamental en la creación de la especialidad.

En diciembre de 2012, el Ministerio de Sanidad, Servicios Sociales e Igualdad (MSSSI) publico el proyecto de Real Decreto por el que se dará paso a la creación de la especialidad de Psiquiatría del Niño y el Adolescente. Cómo se indica en el propio proyecto, con la creación de esta nueva especilidad se garantizará "el derecho de los niños y adolescentes a ser atendidos por médicos es $\neg$ pecializados en esta etapa de la vida, beneficiándose de una evaluación rigurosa y de medidas y recomendaciones apropiadas a su edad".

Es sin duda un logro histórico que promete y nos compromete a nuevos planteamientos y desafíos, de manera muy destacada se encuentra el cambio filosófico y pedagógico que supone el modelo de competencias aplicado a los programas de formación, que integre la nueva filosofía formativa y esté a la altura de las expectativas tan largamente cultivadas y de las necesidades y demandas de la población y los profesionales.

Para ello y como primer paso se tiene que constituir la primera Comisión Nacional de la Especialidad que tendrá que elaborar no solo los criterios para acreditar a los profesionales que quieran acceder a la nueva especialidad y que llevan tiempo trabajando en el ámbito de la Psiquiatría del Niño y del Adolescente sino que, y es lo más importante, tendrá que elaborar el programa formativo de los futuros MIR y acreditar a las futuras Unidades Docentes Multiprofesionales responsables de su formación.

Pese a que en el seno de la AEN-PSM existe una Asociación de Psiquiatras de la Infancia y la Adolescencia, que de manera específica agrupa a psiquiatras que trabajan y acumulan larga experiencia y calidad en esta disciplina, desafortunadamente, hemos sido excluidos la nueva Comisión Nacional cuya gestión se ha producido de forma opaca y sin argumentos que motiven la exclusión y sin respetar los acuerdos realizados en el momento de la creación de la Comisión Gestora. 
EDITORIAL

De igual forma, contraviniendo al Decreto del que el mismo MSSSI se ha dotado, ha sido incluido, como vocal de la Organización Medica Colegial, un pediatra, lo que introduce un sesgo que creíamos largamente superado.

La AEN-PSM continuará luchando con todos los instrumentos necesarios para que su visión multidisciplinar, comunitaria, no medicalizadora, respetuosa con los derechos del niño y la niña, garante de la mejor atención disponible, no falte en la nueva y esperada especialidad.

Mantendremos nuestro compromiso con la mejor formación pregrado, postgrado y continuada para los profesionales que trabajen en este campo, así como con la creación y adecuación de cuantos serviciós se necesiten de acuerdo con las necesidades que marque la epidemiología. Nuestro compromiso trasciende trasversalmente a los profesionales de los distintos ámbitos que desempeñan su labor junto a los menores y sus familias (sanitarios, sociales, y fundamentalmente educativos) que deben poseer la formación necesaria para fomentar actuaciones de tipo preventivo y de promoción de la salud, mediante programas que también deben incorporarse a la formación postgraduada, evitando algunos de los grandes males de los que adolece hoy la atención a la infancia y la adolescencia en salud mental: el sobrediagnóstico, la medicalización y psicologización de conductas no patológicas con sus secuelas estigmatizadoras. 